\title{
Workshop Penguatan Media Pembelajaran Online Onenote Classroom Di Sma Muhammadiyah Kota Sorong
}

\author{
Muhammad Fathurrahman ${ }^{1}$, Muhammad Syahrul Kahar ${ }^{2}$ \\ ${ }^{1,2}$ Universitas Muhammadiyah Sorong \\ Email: r.fathur.ums@gmail.com
}

\begin{abstract}
ABSTRAK
Pemanfaatan Teknologi dan informasi saat ini sangat dibutuhkan dalam peningkatan mutu Pendidikan khususnya di SMA Muhammadiyah Al-Amin Kota Sorong, oleh karena itu perlunya memberikan penguatan kepada para guru dengan cara memberikan pemahaman dan pelatihan kepada para gruu. Pengabdian ini dilakukan dengan mensurvei kemampuan guru dalam hal teknologi, mewawancarai, dan memberikan pelatihan. Hasil yang diperoleh dalam pengabdian ini adalah sebuah platform Microsoft education, dan onenote classroom unutuk masing-masing guru. Dengan memanfaatkan platorm onenote classroom ini dapat meningkatkan kualitas pembelajaran di SMA Muhammadiyah Al-Amin Kota Sorong.
\end{abstract}

Kata Kunci: Onenote Classroom, Microsoft, Pelatihan, Pembelajaran Online.

\section{PENDAHULUAN}

Semakin pesatnya teknologi dan informasi saat ini, menuntut para pendidik untuk lebih giat mengikuti arah perkembangan ini. Proses pembelajaran yang dahulunya masih dilakukan secara tradisional dalam artian dilakukan secara offline, tetapi saat ini dengan memanfaatkan perkembangan teknologi maka proses pembelajaran dapat dikembangkan dengan mengikuti arah perkembangan zaman. Pembelajaran online memiliki banyak manfaat, di mana pembelajaran dapat dilakukan cara yang efektif, cepat, dan efesien. Efesiensi pembelajaran ini dapat dilihat dari mudah guru dan siswa dalam berinteraksi, membagikan materi ajar, memberikan penguatan, motivasi dan lainnya (Tingerthal : 2011). Semua dapat dilakukan dimana saja, dan kapan saja dengan memanfaatkan kecanggihan teknologi saat ini. Sehingga pengtingnya seorang guru sebagai pengajar untuk memiliki keahlian dan penguasaan terhadap Teknologi, khususnya dalam pembelajaran. Sehingga secara tidak langsung pembelajaran yang dilakukan akan lebih bermutu (Weafer : 2006).

Dalam melaksanakan kegiatan pembelajaran, guru wajib mengintegrasikan teknologi informasi dan komunikasi, sehingga guru dapat menghadapi tantangan abad ke 21 ini (Usodo : 2016). Pada abad ke-21 sistem pendidikan akan mengalami pergeseran atau perubahan paradigma, diantaranya adalah dari kampanye buta aksara ke kampanye buta teknologi, budaya dan komputer. Saat ini keberadaan seorang guru dituntut lebih professional. Guru tidak hanya bertindak sebagai pengajar untuk mentrasferkan pengetahuaannya kepada para murid akan tetapi lebih kepada menciptakan kondisi pembelajaran demokratis dan menantang dengan mengintegrasikan penggunaan teknologi pembelajaran, khususnya teknologi informasi dan komunikasi yang dapat diagunakan dalam kegiatan pembelajaran. Namun demikian fakta yang terjadi banyak guru yang tidak banyak yang menguasai teknologi informasi dan komunikasi, khususnya penguasaan penguasaan e-learning dalam pembelajaran. 
Profil pengajar di kota sorong khususnya di SMA Muhammadiyah Kota Sorong, memiliki kemampuan penguasaan teknologi yang baik, akan tetapi belum dimaksimalkan dalam pelaksanaan pembelajaran, padahal di SMA Muhammadiyah Kota Sorong memiki infrastruktur yang medukung pelaksanaan pembelajaran dengan cara online. Salah satu yang dapat dimanfaatkan oleh para guruguru di di SMA Muhammadiyah Kota Sorong yaitu OneNote Classroom, SMA Muhammadiyah Kota Sorong memiliki sebuah website, yang mana dengan website ini sekolah dapat mendaftarkan akun Microsoft education secara gratis di Microsoft. Dengan akun gratis ini maka, sekolah dapat memanfaatkan salah satu fitur Microsoft yang sangat bermanfaat dalam proses pembelajaran dikelas yaitu OneNote Classroom.

Onenote classroom merupakan suatu teknologi yang dapat menggantikan dominasi kertas dan pensil di dalam kegiatan pembelajaran di kelas (Wahyuningsi : 2017). onenote juga memiliki fitur-fitur yang bermanfaat untuk kefektifan pembelajaran pada era modern ini, seperti fitur real time synchronous, dengan fitur ini guru dapat membagikan materi apapun kepada siswa dimana dan kapan saja serta otomatis tersinkron pada perangkat-perangkat milik siswa,

Dalam penelitian yang dilakukan oleh (Turner : 2011) tentang penggunaan onenote, dari hasil kuesioner yang dilakukan, responden menyukai penggunaan onenote dengan alasan menggunakan OneNote mereka tidak akan kehilangan catatan yang mereka tulis karena catatan yang dimasukkan akan tersimpan secara otomatis, tidak seperti menggunakan lembar kertas. Selain itu onenote memiliki fitur colaborasi yang dapat dimanfaatkan baik itu siswa mampun guru, dengan fitur ini guru dapat berkolaborasi dengan guru lain yang memiliki bidang ilmu yang sama untuk menyediakan materimateri secara lengkap untuk siswanya, siswapun dapat berkolaborasi dengan siswa lain dalam hal berdiskusi atau mengerjakan tugas secara bersama-sama (Campbell : 2018)

Oleh karena itu pada pengabdian ini penulis akan memberikan pelatihan kepada para guru di di SMA Muhammadiyah Kota Sorong terkait pemanfaatan OneNote Classroom dalam pembelajaran. Diharapkan setelah guru-guru mengikuti pelatihan ini, para guru dapat memanfaatkan media pembelajaran ini dengan baik, sehingga pembelajaran dapat berjalan dengan efektif dan efisien, serta kualitas Pendidikan di SMA Muhammadiyah Al-Amin menjadi lebih baik dan dapat bersaing ditengah lajunya perkembangan teknologi di abad 21 ini.

\section{METODE}

Kegiatan ini dilaksanakan di SMA Muhammadiyah Al Amin Kota Sorong pada bulan Juni 2019 dengan jumlah peserta 18 orang. Kegiatan ini juga didampingi oleh narasumber yang memiliki kompetensi yang dibutuhkan dalam memberikan petunjuk pelaksanaan workshop Pemanfaatan Microsoft onenote classroom. Adapun target dalam kegiatan ini dihaarapkan peserta mampu memahami tahapan pengelolaan kelas dengan memanfaatkan aplikasi Microsoft melalui tahapan demonstrasi dan Praktek, dimana peserta diberikan penjelasan berupa demonstrasi pemanfaatan 
Microsoft onenote selanjutnya dilakukan proses pendampingan secara berkesinambungan agar peserta mampu memahami cara penggunaannya.

\section{HASIL DAN PEMBAHASAN}

Kegiatan pengabdian kepada masyarakat ini dilakukan dengan cara wawancara, pelatihan dan demonstrasi. Kegiatan ini dilaksanakan di SMA Muhammadiyah Al-Amin Kota Sorong. Kegiatan di mulai dengan melakukan survei lapangan untuk tahap penyusunan rencana kerja. Kegiatan survei ini dilakukan guna untuk mengidentifikasi permasalahan yang ada di SMA Muhammadiyah Al-Amin Kota Sorong yang dapat dicarikan solusinya dengan kegiatan pengabdian masyarakat. Pada pelaksanaanya akan diberikan materi tentang kepahaman OneNote classroom kepada seluruh guru SMA Muhammadiyah Al-Amin, hal ini agar para guru dapat memiliki keterampilan sebagai berikut :

1. Membuat kelas online pada OneNote classroom

2. Memasukkan murid pada kelas online

3. Masukkkan materi pada kelas online

4. Memasukkan soal evaluasi pada kelas online

5. Melakukan Evaluasi pada hasil pembelajaran siswa pada kelas online

Dari hasil pelaksanaan pengabdian ini luaran yang diperoleh adalah sebuah platform aplikasi OneNote classroom SMA Muhammadiyah Al-Amin Kota Sorong.

1. Halaman dasboard

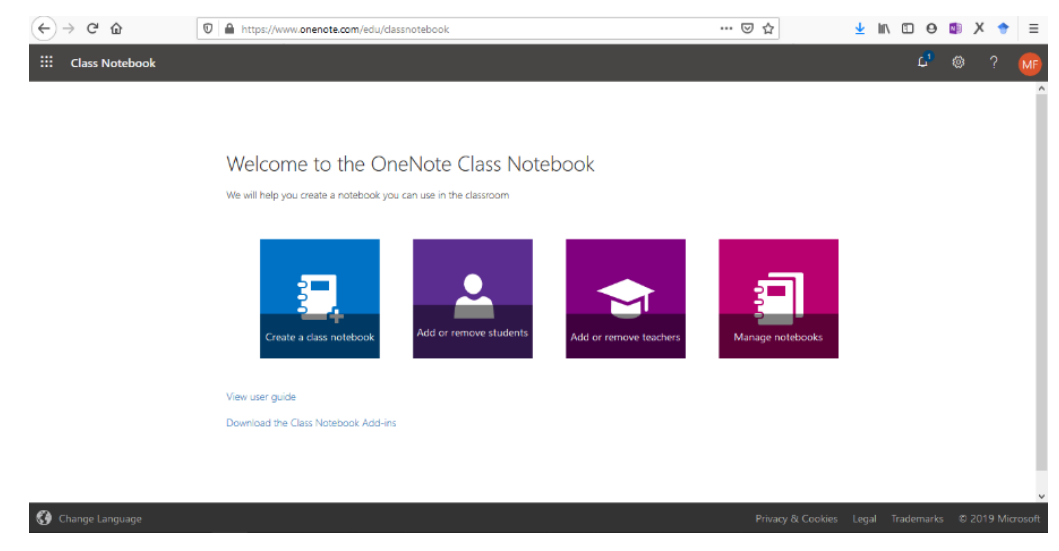

Gambar 1. Halaman Dasboard

Pada halaman ini guru dapat membuat kelas online, menambah siswa pada kelas online, menambah guru pendamping pada kelas online, dan mengeditnya kembali jika diperlukan.

2. Tampilan kelas online 


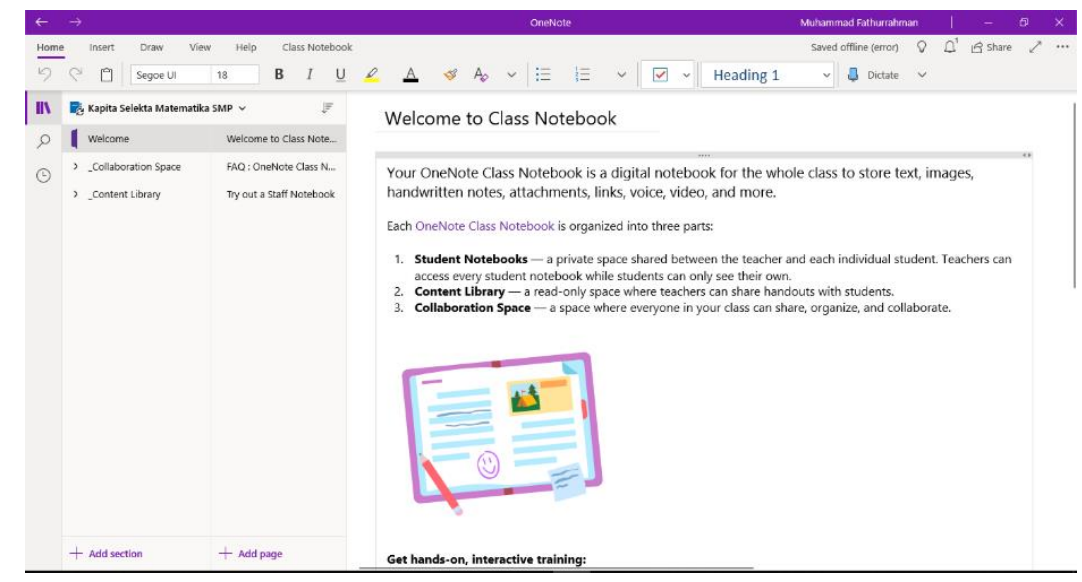

Gambar 2. Tampilan kelas online

Ini merupakan tampilan awal ketika baru membuat kelas online.

3. Tampilan kelas online yang telah diedit

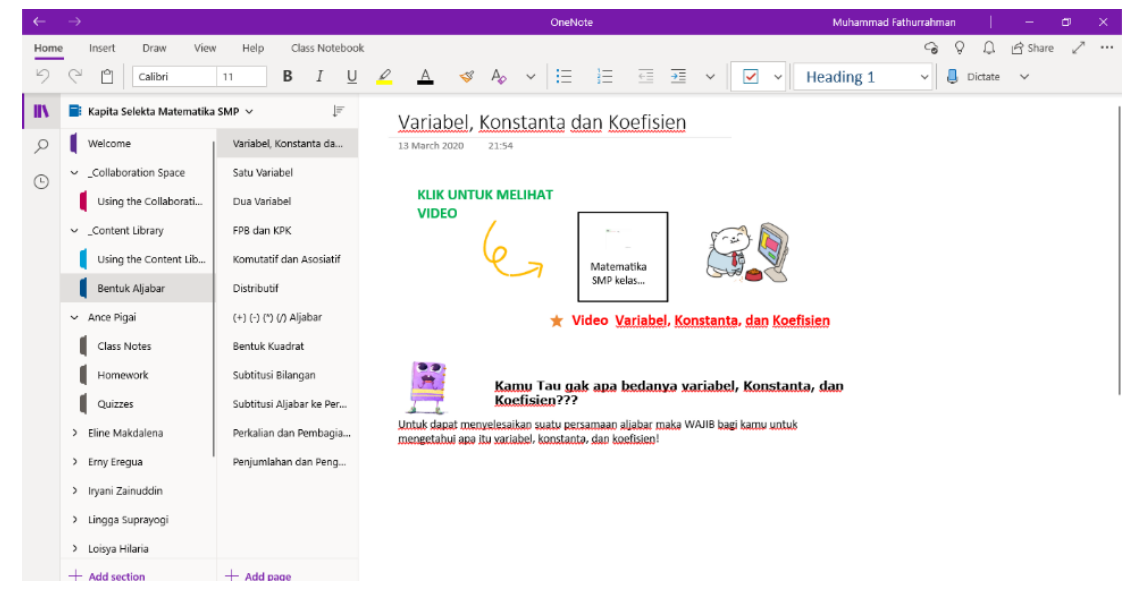

Gambar 3. Tampilan OneNote Classroom setelah dikembangkan

Setelah memasukkan materi dan tugas pada kelas online, maka tampilannya akan seperti gambar diatas.

Kelas online ini terdiri dari 3 bagian yaitu:

a. Student Notebooks - ruang pribadi dibagi antara guru dan setiap siswa. Guru dapat mengakses setiap buku catatan siswa sementara siswa hanya dapat melihat buku catatan mereka sendiri.

b. Materi-Materi — ruang baca-saja di mana guru dapat berbagi berbagai artikel (document, persentasi, pdf, video, audio) dengan siswa.

c. Diskusi dan Absensi - ruang di mana setiap orang di kelas Anda dapat berbagi, mengatur, dan berkolaborasi serta dapat menginput kehadiran pada kelas digital (Salman : 2014). 


\section{Simpulan}

Workshop ini dilakukan untuk dapat mengenalkan para guru di SMA Muhammadiyah AlAmin Kota Sorong dengan media pembelajaran online seperti OneNote Classroom agar kualitas pembelajaran pada sekolah dapat lebih maksimal. Diharapkan para guru untuk kedepannya membiasakan diri untuk lebih memaksimalkan penggunaan media pembelajaran ini, dan dapat mengembakan media pembelajaran ini, agar supaya media pembelajaran ini lebih baik lagi.

\section{Daftar Pustaka}

Campbell, J., \& Duplice, J. (2018). OneNote Class Notebook for Teachers at Multiple Universities in Japan. 英語教育研究所紀要 (CELE Journal $)=$ CELE JOURNAL, (26), 30-36.

Usodo, B., Sutopo, S., Chrisnawati, H. E., Kurniawati, I., \& Kuswardi, Y. (2016). Pelatihan Penerapan Beberapa Aplikasi dari Microsoft: Office Mix, Onenote, Sway dalam Pembelajaran bagi Guru-Guru Matematika SMA di Kabupaten Sragen (Doctoral dissertation, Sebelas Maret University).

Salman, I. S. (2014). OneNote in education: An effective way to enhance approaches of teaching and learning in classroom.

Tingerthal, J. S., \& SE, P. (2011). Using Tablet PCs as a teaching tool in the CM classroom. In 47th ASC Annual International Conference Proceedings.

Turner, J. (2011). Using Microsoft OneNote for Collaborative Vocabulary Notebooks in the Academic English Classroom.

Weaver, A. C. (2006, October). Does Classroom Presenter Software Change Learning Outcomes?. In Proceedings. Frontiers in Education. 36th Annual Conference (pp. 1014). IEEE.

Wahyuningsih, P. (2017). Kemampuan Literasi Matematika Berdasarkan Metakognisi Siswa pada Pembelajaran CMP Berbantuan Onenote Class Notebook. Unnes Journal of Mathematics Education Research, 6(1), 18-29. 